\title{
A study on the relationship between working memory capacity, L2 vocabulary size, and L2 listening proficiency
}

\author{
Koeon Yi, School of Education, Jeonju University, 303 Cheonjam-ro, Wansan-gu, Jeonju, 55069, Republic of \\ Korea \\ *Sunhee Choi, School of Education, Jeonju University, 303 Cheonjam-ro, Wansan-gu, Jeonju, 55069, Republic \\ of Korea, sunheech@jj.ac.kr \\ *Corresponding Author
}

\begin{abstract}
The purpose of this study is to find out how working memory is related to English vocabulary size and listening comprehension of Korean EFL (English as a Foreign Language) learners. 30 college students, all English education majors, were recruited for the study. In this experiment, the backward digit span task and the operation span task were used to measure the participants' working memory capacity. The Listening Vocabulary Level Test (LVLT) and the Michigan English Test (MET) were adopted to measure their vocabulary size and listening proficiency, respectively. To analyze the data, both descriptive and inferential statistics, in particular the correlational analysis, were employed. The results show that there is quite a variation in the participants' storage capacity, which was confirmed by the relatively high standard deviations. The correlational analyses reveal that the bigger one's working memory storage is, the better the person processes incoming input. However, there was no statistically significant correlation between working memory capacity, English vocabulary size, and listening proficiency, which might have been caused by the fact that a small group of relatively homogeneous subjects participated in the study. Follow-up studies with bigger and diverse samples should look at what factors interacts with L2 listening that can affect listening skills in addition to L2 vocabulary knowledge.
\end{abstract}

Keywords: Working memory capacity, L2 vocabulary size, L2 listening ability, Second language learning, Correlational analysis

Received: 07.12.2020

Accepted: 16.01 .2021

Published: 05.02.2021

\section{INTRODUCTION}

When learning English as a second language or foreign language (L2), listening ability is one of the essential prerequisites for successful communication as well as an important source for one's interlanguage development. As Krashen suggests, we acquire a language when we are exposed to a lot of language samples that we comprehend [1]. Therefore, identifying the variables that affect English listening skill is very important not only for teaching English listening effectively, but also for helping learners develop their second language abilities. Various factors influence second language listening including language knowledge, the ability to focus on incoming sounds, and general cognitive ability [2]. In addition, native language listening comprehension skills, background knowledge, vocabulary ability, meta-cognition, and working memory capacity are known to have impact on L2 listening comprehension $[3,4,5,6,7]$.

Among these variables, working memory is considered to be playing an important role in processing new information including L2 input [8]. A number of studies have been conducted in order to figure out the impact of working memory on second language learning. However, most studies have focused on the effect of working memory on reading or the correlation between working memory and vocabulary learning, while very little has been done on the relationship between working memory capacity and L2 listening comprehension [9]. The purpose of this study, therefore, is to investigate how working memory is related to English listening comprehension of Korean EFL (English as a Foreign Language) college learners.

\section{Materials and Methods}

The current study was conducted with 30 English education majors who were studying at a four-year university located in Jeonju, Korea at the time of the study. Participants were recruited one month prior to the experiment through an advertisement on campus. The experiment was conducted for two weeks from May 13 to May 24, 2019. The students who participated in the study completed the study participation agreement prior to the experiments. 


\subsection{Participants}

The participants consisted of 21 female (70\%) and 9 male students (30\%). There were 14 freshmen (46.7\%), 2 sophomores $(6.7 \%), 10$ juniors $(33.3 \%)$, and four seniors $(13.3 \%)$. When asked about their level of English proficiency, 25 students (83.3\%) said that their level was intermediate, while two students answered that they were at the advanced level and three students answered their English proficiency was low. This suggests that the participants were not too confident about their English proficiency.

\subsection{Measurements}

In this study, the backward digit span task and the operation span task were used to measure the participants' working memory capacity. Both of them have been enjoying popularity among working memory researchers due to their robustness. With the backward digit span task, which measures one's storage capacity, a subject is required to listen to consecutive numbers and then say the numbers in the reverse order. For example, if you hear nine and four in a recorded voice, you should say four and nine to get a score. The numbers were presented in from two to nine digits, and were played randomly without increasing the numbers sequentially in order to prevent subjects from using memory strategies. The operation span task, which measures both storage and information processing capacity, was used with a computer. In the test, the participants were asked to solve arithmetic problems and then remember the alphabet shown on the screen afterwards. Figure 1 illustrates how the operation span task was conducted.

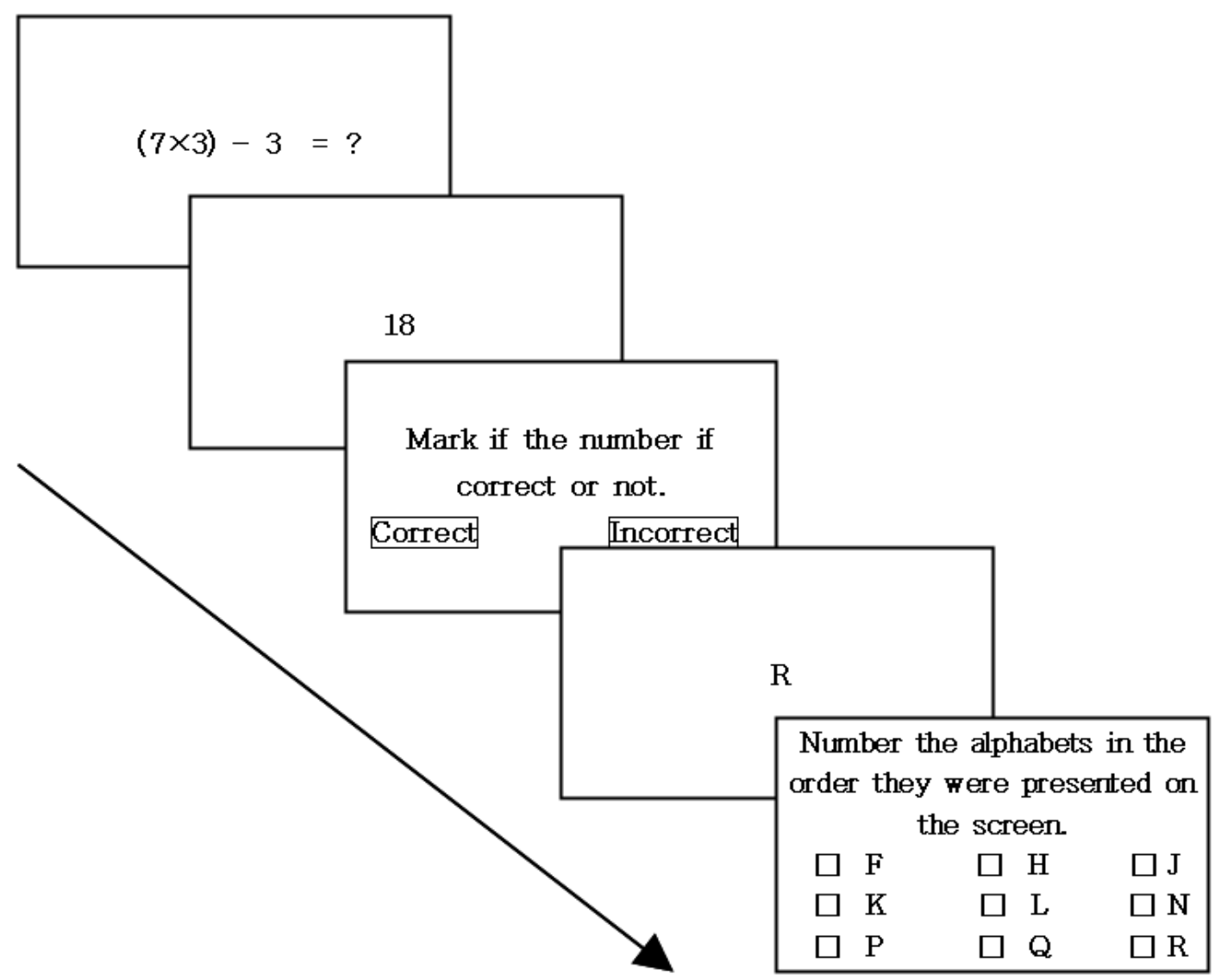

Figure 1 The Flow of the operation span task

The Listening Vocabulary Level Test (LVLT) $[10,11]$ was employed to measure the participants' vocabulary skills. The test consists of 5,000 high frequency words from stage 1 to stage 5 and academic vocabulary as well, which are derived from British National Corpus (BNC) and the Corpus of American English (COCA) [12]. The 5000 high frequency words used in the LVLT account for approximately 96 to $97 \%$ of daily English conversation [13]. With the LVLT, subjects listen to a word and a sentence in which 
the word is used, and then have to choose the correct meaning in Korean among four options. In addition, the Michigan English Test (MET) developed by the University of Michigan was adopted to assess the students' listening proficiency. The MET's listening test has a total of 50 questions that are based on everyday conversations of American speakers. In order to evaluate test takers' fluency in English, the listening test consists of conversations occurring in their daily lives, such as at school and work. The test is divided into three parts: Part 1 is a matter of listening to and solving a short conversation questions, and Part 2 is about listening to a long conversation and solving three or four problems. Part 3 is to listen to one person's discourse and solve four or five questions. Scoring was proceeded by counting the number of questions answered correctly. Detailed information regarding the measurement tools used in this study is shown in Table 1.

Table 1 Measurement tools

\begin{tabular}{llll}
\hline Measurement Targets & Tools & No. of Items & Total Score \\
\hline Working Memory & Backward Digit Span Task & 30 & 30 \\
& Operation Span Task & 16 & 16 \\
Listening Vocabulary & LVLT & 126 & 126 \\
Listening Proficiency & MET & 50 & 50 \\
\hline
\end{tabular}

\section{Results and Discussion}

In this study, two methods were utilized to assess the working memory capacity of the participants. In order to measure the simple storage capacity, the backward digit span task was used while the operation span task was used to assess both storage and information processing ability. Both tests were scored by giving one point only if the participants remembered exactly the numbers or letters presented. As shown in Table 2, the participants scored an average of 16.63 points out of a total of 30 points in the test of the simple storage capacity. Considering the large standard deviation of 3.755 , it is apparent that there are significant individual differences in the storage capabilities among the study participants. In contrast, the combined capacity test results, which measure storage capacity and processing capacity simultaneously, showed a relatively high average of 11.93 out of 16 points. Interestingly, the study participants had a minimum score of 5 and a maximum score of 16 . This also indicates that there is quite a variation in participants' processing capacity, which can be confirmed by the relatively high standard deviation of 2.803 .

Table 2 Participants' working memory capacity

\begin{tabular}{llllll}
\hline Working Memory Tests & N & Min. & Max. & M & SD \\
\hline Backward Digit Span Task $(k=30)$ & 30 & 11 & 25 & 16.63 & 3.755 \\
Operation Span Task $(k=16)$ & 30 & 5 & 16.00 & 11.93 & 2.803 \\
\hline
\end{tabular}

As discussed above, the vocabulary abilities of the participants were measured using the Listening Vocational Levels Test (LVLT). The LVLT is a test that gives learners words and allows them to choose their meaning. The test consists of a total of six parts, but the present study did not use Level 1 , which measures the knowledge of words belonging to the General Service List's 1,000 vocabulary groups, considering the fact that the participants were majoring in English education and were believed to already possess basic vocabulary skills. Instead, it included an Academic Vocabulary test, which measures the vocabulary skills required when they study using English-language textbooks.

As illustrated in Table 3, the learners' scores were quite high in the low-level vocabulary test. The 
average for the 2,000 word level test was 22.63 out of 24 points, and the average for the 3,000 word level test was 21.40. Given that these two levels of standard deviation are also 1.129 and 1.714, respectively, we can see that there are no significant differences in learners' vocabulary abilities at these two levels. On the other hand, at the higher levels of 4,000 words and 5,000 words, the mean was lower at 18.23 and 18.20 respectively, and the standard deviations ware 3.070 and 2.140 respectively, showing some individual differences among the participants. What is interesting is that the average of the academic vocabulary test, which generally includes more difficult words, is considerably higher at 27.23 , and the standard deviation is also lower at 1.736. This is probably because the participants were exposed to this level of vocabulary while preparing for the College Scholastic Ability Test and also because they had been taking classes using English-language textbooks in their program.

Table 3 The Results of English vocabulary test

\begin{tabular}{lccccc}
\hline Levels & N & Min. & Max. & M & SD \\
\hline 2,000 words $(k=24)$ & 30 & 20 & 24 & 22.63 & 1.129 \\
3,000 words $(k=24)$ & 30 & 18 & 24 & 21.40 & 1.714 \\
4,000 words $(k=24)$ & 30 & 11 & 24 & 18.23 & 3.070 \\
5,000 words $(k=24)$ & 30 & 12 & 21 & 18.20 & 2.140 \\
Academic Vocabulary $(k=30)$ & 30 & 21 & 29 & 27.23 & 1.736 \\
Total Score $(k=126)$ & 30 & 87 & 118 & 107.70 & 7.250 \\
\hline
\end{tabular}

The participants' English listening skills were measured using the Michigan English Test (MET). The test consists of three parts: Part I is listening to a short conversation between two people, Part II is listening to a long conversation, and Part III is solving a problem after listening to one person's discourse. As displayed in Table 4, the participants scored the average of 10.27 out of 14 for long conversations, and scored the average of 8.77 out of 19 for short conversations. The long conversations are longer and consequently, may include many clues, which is assumed to have made it easier for the participants. In a personal conversation with the researchers, the participants mentioned that the pace of the conversations was considerably faster than the College Scholastic Ability Test or TOEIC that they were familiar with, which may have also contributed to lowering the students' scores.

Table 4 The Results of English Listening Comprehension Test

\begin{tabular}{llllll}
\hline aarts & $\mathbf{N}$ & Minimum & Maximum & Means & SD \\
\hline Part I $(k=19)$ & 30 & 4 & 16 & 8.77 & 2.837 \\
Part II $(k=14)$ & 30 & 7 & 13 & 10.27 & 1.530 \\
Part III $(k=17)$ & 30 & 2 & 15 & 8.80 & 3.134 \\
Total Score $(k=50)$ & 30 & 16 & 42 & 27.83 & 6.654 \\
\hline
\end{tabular}

Table 5 provides the results of a Pearson correlation analysis of the participants' working memory, English vocabulary, and English listening ability scores. First, the two working memory 
measurements showed a significant correlation of $r=0.364(\mathrm{p}<.05)$. These results indicate that there is a statistically meaningful relationship between the two working memory measuring tools, which means that the study participants' simple storage capabilities and complex processing capabilities are related. In other words, the ability to process information is high if the storage capacity of the working memory is high. Similarly, there is a statistically significant correlation between the English vocabulary score and the English listening ability $(\mathrm{r}=.448, \mathrm{p}<.05)$. This is consistent with the results of the existing studies $[7,14]$, which means that learners with a lot of vocabulary are also good at listening to English discourses.

Table 5 The correlation between working memory, English vocabulary, and English listening ability

\begin{tabular}{lllll}
\hline & $\begin{array}{l}\text { Backward } \\
\text { Digit Span }\end{array}$ & Operation Span & $\begin{array}{l}\text { English } \\
\text { Vocabulary }\end{array}$ & $\begin{array}{l}\text { English Listening } \\
\text { Ability }\end{array}$ \\
\hline $\begin{array}{l}\text { Backward Digit } \\
\text { Span }\end{array}$ & 1.00 & $.364^{*}$ & .211 & .174 \\
Operation Span & & .203 & .009 \\
$\begin{array}{l}\text { English } \\
\text { Vocabulary }\end{array}$ & & & \\
English Listening & & & $.448^{*}$ \\
Ability & & & 1.00 \\
$* p<.05$ & & &
\end{tabular}

However, no statistically significant correlation was found between working memory, English vocabulary, and English listening ability. These results are different from the previous studies [15, 16], which reported that there was a correlation between the two variables. One of the reasons for this result is that the sample size of this study is relatively small. While [15] was conducted with 210 foreign language learners, the current study involved only 30 people. Another reason may be related to the procedures of measuring the working memory of the participants. When measuring work memory, the researchers provided a bit more time for participants to solve each task than suggested in the previous studies, which is likely to allow the participants to use a strategy to remember numbers or characters to achieve better performance results. It is also possible that the participants' English skills have already reached at a certain level where they are least likely to be affected by their working memory. That is, because the most participants have more than 10 years of English learning experience and already have a significant amount of vocabulary knowledge, it is possible that even if the working memory is not large enough, they did not have much trouble listening to or understanding English words or conversations. This can be seen from the fact that the participants' English vocabulary and listening skills have a meaningful correlation.

\section{Conclusion}

The present study aimed to discover how working memory and English vocabulary are related to listening skills of Korean EFL learners, and the results are as follows.

First, the results of the experiment show that the scores of backward digit span task and those of the operation span task had a significant relationship. This means that the study participants' simple storage capabilities and complex processing capabilities are related, indicating that they are also highly capable of processing information when the storage capacity of the working memory is high. Second, there is also a statistically significant correlation between the English vocabulary size and the English listening ability. This means that students with good knowledge of English vocabulary are good at listening to English. Third, there was no statistically significant correlation between the working memory, English vocabulary, and English listening ability.

For future research on the relationship between working memory and L2 listening ability, the following suggestions can be made. First, the sample size of this study was not large enough to produce 
meaningful results. Therefore, it is necessary to have a bigger sample size. Second, the participants of the present study did not seem to rely much on their working memory in English vocabulary and listening comprehension tests, as they had achieved higher levels in these areas as English education majors. Therefore, it is proposed to study with non-English majors or learners of different ages. Finally, follow-up studies should look at what factors interact with L2 listening, including meta-cognition, test-taking strategies, and listening strategies in addition to L2 vocabulary knowledge.

\section{References}

[1] Krashen, S. The input hypothesis: Issues and implications. London: Longman; 1985.

[2] Daneman, M. \& Merikle, P. M. Working memory and language comprehension A meta-analysis. Psychonomic Bulletin \& Review. 1985;3:422-433.

[3] Andringa, S., Olsthoorn, N., van Beuningen, C., Schoonen, R., \& Hulstijn, J. Determinants of success in native and non-native listening comprehension: An individual differences approach. Language Learning. 2012;62(2):49-78.

[4] Conway, A. R. A., Cowan, N., Bunting, M. F. The cocktail party phenomenon revisited: the importance of working memory capacity. Psychonomic Bulletin \& Review. 2001;8(2): 331- 335.

[5] Vandergrift, L. Second Language Listening: Listening ability or language proficiency? The Modern Language Journal. 2006;90:6-18.

[6] Vandergrift, L. Recent developments in second and foreign language listening comprehension research. Language Teaching. 2007;40(3):191-210.

[7] Vandergrift, L., \& Baker, S. Learner variables in second language listening comprehension: An exploratory path analysis. Language Learning. 2015;65(2): 390-416.

[9] Baddeley, A. D. Working memory and language: An overview. Journal of Communication and Disorders. 2003;36(3):189-208.

[10] Choi, S. Working Memory and the Learning of English as a Foreign Language: Current Research Practices and Future Directions. Studies on English Language \& Literature. 2019;45(1):415-437.

[11] McLean, S., Kramer, B., \& Beglar, D. The creation and validation of a listening vocabulary levels test. Language Teaching Research. 2015;19(6):741-760. doi: 10.1177/1362168814567889.

[12] McLean, S., Hogg, N., \& Kramer, B. Estimations of Japanese university learners' English vocabulary sizes using the Vocabulary Size Test. Vocabulary Learning and Instruction. 2014;3(2):47-55.

[13] Nation, I. S. P. Learning vocabulary in another language. Cambridge: Cambridge University Press; 2001.

[14] Nation, I. S. P. How large a vocabulary is needed for reading and listening? The Canadian Modern Language Review. 2006;63(1):59-82.

[15] Andringa, S., Olsthoorn, N., van Beuningen, C., Schoonen, R., \& Hulstijn, J. Determinants of success in native and non-native listening comprehension: An individual differences approach. Language Learning. 2012;62(S2):49-78.

[16] Miki, S. Working memory as a factor affecting L2 listening comprehension sub-skills. Kumamoto University Departmental Bulletin Paper. 2012;10:119-128.

[17] Kormos, J., \& Sáfár, A. Phonological short-term memory, working memory and foreign language performance in intensive language learning. Bilingualism: Language and Cognition. 2008;11(2):261271. 